\title{
Políticas, CRENÇAS E ATITUdES LINGUísticAs EM CONTEXTO MULTILÍNGUE
}

Adriana Dalla Vecchia*

LETÍCIA FragA**

\section{RESUMO}

Neste artigo, demonstramos como ocorre a relação entre as políticas linguísticas adotadas pela Colônia Entre Rios, em Guarapuava-PR, e as crenças dos falantes das diferentes línguas em contato na região. Tendo em vista essa reflexão, também abordamos o ensino de línguas a partir da influência dessa relação, procurando mostrar que a hibridização linguística não coopera para o bilinguismo ideal (português/alemão clássico), pelo contrário, estorva a prática deste e a variedade local de língua alemã é a responsável pela realização problemática do alemão clássico. Para tanto, apoiamo-nos, especialmente, nas orientações de Calvet (2007), Finger (2008) e Barcelos (2004; 2006).

Palavras-chave: políticas linguísticas, crenças e atitudes linguísticas, ensino de línguas, contexto multilíngue.

\section{INTRODUÇÃO}

Este artigo demonstra a relação entre as políticas linguísticas (CALVEt, 2007) adotadas e as crenças dos falantes das diferentes línguas em contato na Colônia Entre Rios, comunidade de origem alemã/ suábia, um distrito de Guarapuava-PR. Tendo em vista que nesse local as escolhas linguísticas são bastante singulares e guiam o ensino de línguas na escola, é possível falarmos em políticas e planejamento lin-

* Mestre em Linguagem, Identidade e Subjetividade pela Universidade Estadual de Ponta Grossa-PR (2013) e Professora na Faculdade Campo Real, em Guarapuava-PR.

E-mail: adrianarevisao@gmail.com

** Professora Adjunta da Universidade Estadual de Ponta Grossa e coordenadora do Mestrado em Linguagem, Identidade e Subjetividade na mesma instituição.

E-mail: leticiafraga@gmail.com 
guísticos. Essa discussão é parte da pesquisa de mestrado, defendida por uma das autoras, resultado do trabalho de pesquisa posta em prática no período de fevereiro de 2011 e fevereiro de 2013.

Com base na discussão sobre políticas e crenças linguísticas na região, é de suma importância, para que o leitor tenha maior clareza da situação linguística complexa em que vivem os suábios e os demais moradores de Entre Rios, delinearmos também o ensino de línguas a partir da influência dessa relação. Faremos esse mapeamento, bem como detalharemos as políticas locais a partir do item 3 deste texto: Crenças e atitudes para a instituição de políticas linguísticas locais.

De antemão, vale dizer que as decisões locais relativas ao uso das línguas na comunidade servem às necessidades, aos interesses e desejos dos próprios moradores, as quais são estabelecidas e mantidas, em grande parte, pela atuação da instituição escolar mantida pelo grupo linguístico. Ou seja, lá é colocado em prática o que a comunidade entende como benéfico sobre ensino de línguas para a vivência no local e para manter suas relações com a Alemanha, vínculo estreitado pela Agrária Agroindustrial (doravante CAA), cooperativa que é centro econômico da região.

As escolhas linguísticas estão atreladas, em grande parte, à forma como as línguas em contato são vistas e interpretadas pelos seus falantes e, sobretudo, por aqueles que detêm o poder de colocar essas escolhas em prática, no caso, o Governo Alemão, a CAA e o Colégio Imperatriz Dona Leopoldina. Tais decisões acerca da língua são tomadas com base nas crenças da equipe pedagógica que refletem também as da comunidade como um todo. A partir delas, é construído o Projeto Político Pedagógico (doravante PPP) que, como instrumento da política linguística local, põe em prática essas decisões. O documento baseia-se, ainda, no Quadro Europeu Comum de Referência (QECR) para conferir credibilidade, sobretudo, ao ensino de língua alemã, chamando para o Colégio da comunidade a responsabilidade no que se refere aos testes de proficiência em alemão, organizados e avaliados por pessoal do Governo Alemão.

Para efetivar essas reflexões e demonstrarmos o olhar a partir do qual vemos a situação de Entre Rios, apoiamo-nos nas orientações 
provenientes de Calvet (2007), Finger (2008) e Barcelos (2004; 2006), entre outros estudos relativos à temática deste artigo.

\section{CARACTERIZAÇ̃̃o DA METOdOLOGIA DE PESQUiSA}

Esta pesquisa se localiza dentro do campo da Linguística Aplicada (LA), com característica qualitativa-interpretativista de cunho etnográfico. Trata-se de uma interpretação situada historicamente, que busca contribuir, de forma acadêmica, para compreender o lugar das línguas no espaço escolar, as quais acabam por também determinar o lugar de seus falantes e a função do professor no estabelecimento e na manutenção das políticas linguísticas vigentes na instituição e na comunidade.

Dentre os vários instrumentos oferecidos pelas pesquisas de cunho etnográfico, especialmente as que envolvem crenças, optou-se por aqueles que forneceriam dados pertinentes à situação investigada $\mathrm{e}$ que permitissem um desenvolvimento adequado da pesquisa qualitativa. Desse modo, a coleta de informações foi feita a partir de análise documental, entrevista semiestruturada, observações em aulas, diário e gravações em áudio e/ou vídeo. Utilizamos ainda o questionário fechado que, embora não faça parte dos instrumentos de pesquisa etnográfica e possa parecer controversa sua escolha, foi de grande auxílio para mensurar quantos indivíduos, estudantes desde o $7^{\circ}$ ano do Ensino Fundamental II até o $3^{\mathrm{a}}$ ano do Ensino Médio (117 participantes responderam ao questionário), são multilíngues, bilíngues e/ou monolíngues. A partir do instrumento, também conseguimos constatar a situação de bilinguismo e multilinguismo desenvolvida na Colônia, pois nos informam quantas línguas cada participante afirma conhecer e falar.

Participaram desta pesquisa um representante da comunidade e outro da mantenedora, os quais puderam fornecer dados bastante significativos em relação ao papel desempenhado pela instituição escolar dentro da Colônia. Na escola, participaram da fase de entrevistas: a) dois membros da coordenação pedagógica; b) cinco professores de língua alemã e três de língua portuguesa; e c) quatro alunos indicados pela coordenação de alemão a participar das entrevistas devidamente autorizadas por seus responsáveis legais. A identidade dos participantes foi 
preservada, conforme orienta a resolução n. 196 de 10/10/1996 do Conselho Nacional de Saúde; por isso, utilizamos pseudônimos para nos referirmos a eles (ver Quadro 1). Como vimos acima, treze é o número de participantes entrevistados e 117 de participantes que responderam ao questionário, entretanto, neste texto, não foram analisados dados de todos eles, então, fizemos o quadro abaixo, caracterizando apenas os que aqui são mencionados.

Quadro 1. Perfil dos participantes entrevistados

\begin{tabular}{|l|l|l|l|}
\hline Pseudônimo & Função & $\begin{array}{l}\text { Formação e grau de } \\
\text { escolaridade }\end{array}$ & Ascendência \\
\hline Eliane & Professora de alemão & Letras Português/Alemão & Germânica \\
\hline Jane & Professora de Alemão & Letras Português/Alemão & Germânica/suábia \\
\hline Everton & $\begin{array}{l}\text { Professora } \\
\text { de Português }\end{array}$ & $\begin{array}{l}\text { Letras Português } \\
\text { Especialização } \\
\text { Mestrado em andamento }\end{array}$ & Brasileira \\
\hline Rafael & $\begin{array}{l}\text { Professor de Alemão } \\
\text { de Português }\end{array}$ & Letras Português/Alemão & Germânica \\
\hline Andreia & $\begin{array}{l}\text { Professora } \\
\text { de Português }\end{array}$ & $\begin{array}{l}\text { Letras Português } \\
\text { Andersôs }\end{array}$ & Brasileira \\
\hline Marília & $\begin{array}{l}\text { Coordenador } \\
\text { pedagógico }\end{array}$ & $\begin{array}{l}\text { Letras Português/Alemão } \\
\text { Especialização }\end{array}$ & Germânica \\
\hline pedagógica & $\begin{array}{l}\text { Representante } \\
\text { da Mantenedora }\end{array}$ & $\begin{array}{l}\text { Pedagogia } \\
\text { Especialização }\end{array}$ & Germânica/suábia \\
\hline Pedro & Germânica/suábia \\
\hline
\end{tabular}

A pesquisa de campo, desde a fase inicial de contato com os possíveis participantes até as entrevistas e observações em sala de aula, ocorreu entre junho de 2011 e setembro de 2012, com todas as etapas realizadas no Colégio Imperatriz Dona Leopoldina. As visitas e as abordagens da equipe da escola só tiveram início após a aprovação do projeto de pesquisa na Comissão de Ética em Pesquisa (COEP) da instituição, à qual está ligado o programa de mestrado em que as autoras eram uma acadêmica e a outra, docente e orientadora do estudo.

$\mathrm{Na}$ primeira fase, foram entrevistados respectivamente os docentes de língua alemã; os de língua portuguesa; os alunos e só, então, a equipe pedagógica. Após a conversa com os professores, iniciaram 
as observações em sala de aula, visto que procurávamos, primeiro, conhecer o professor, entrevistá-lo para depois começarmos a observação da sua aula. Essa precaução foi tomada para que o professor ficasse mais à vontade com a pesquisadora, o que não chegou a ser uma regra, pois, apesar de conhecê-la com antecedência, não houve um que tenha ficado à vontade com sua presença em sala de aula. Somente o tempo de convívio foi capaz de minimizar essa situação, mesmo assim, temos consciência de que a prática observada dos docentes talvez não corresponda à que ocorre no dia a dia sem a nossa presença. Para a análise e para os objetivos da pesquisa, essa ocorrência não foi de todo ruim, as práticas da maneira como aconteceram foram de extrema importância para as nossas considerações.

2. Breve histórico da Colônia de Imigração Entre Rios EM GuARAPUAVA/PR: ÊNFASE AO ESTABELECIMENTO DE POLÍTICAS LINGUÍSTICAS

Os habitantes da colônia Entre Rios, fundada em 1950, são também identificados como Suábios do Danúbio, expressão que designa grupos populacionais de etnia alemã, do antigo Império Austro-Húngaro, o qual abrigava povos oriundos de diferentes províncias do Reino Alemão e não apenas da Suábia (ElFES, 1971). Os imigrantes partilham uma mesma língua, o Schwowisch ou Suábio, conforme é denominado por eles mesmos. É pertinente esclarecer aqui que, para os participantes da pesquisa, o suábio não tem status de língua, tanto é que se referem a ele como dialeto.

A língua alemã oficial da Alemanha é também denominada Hochdeutsch (alto alemão, alemão clássico ou ainda alemão padrão, segundo os participantes da pesquisa), identificada como uma língua de maior status pelos participantes da pesquisa. Embora possam ser notadas sensíveis diferenças entre o Hochdeutsch e suas variedades, como explicam os professores de alemão do Colégio Imperatriz Dona Leopoldina, os falantes das diferentes variedades se entendem razoavelmente bem entre si e com os usuários da língua padrão, já que as palavras têm a mesma raiz. A crença dos participantes e da comunidade como um todo de que o Hochdeutsch é a mais importante das varieda- 
des levou à estruturação do PPP e da matriz curricular do colégio, cuja maior preocupação, e mais especificamente da área de alemão, é levar os alunos a uma verdadeira proficiência nessa variedade de língua a fim de proporcionar-lhes o acesso a melhores condições de trabalho e/ou graduação na Alemanha. Pela forma como os professores se expressam, fica evidente que eles acreditam que o ensino de Hochdeutsch tem um papel fundamental para que os alunos obtenham sucesso profissional.

Nesse ponto, abrimos um parêntese, pois convém explicar que o sucesso profissional está unido, em geral, ao ingresso desse aluno, quando formado, na CAA, atuando em cargos variados a depender da demanda. Ela foi fundada em 6 de maio de 1951, com o intuito de suprir a falta de rendimentos dos imigrantes que era urgente; a Cooperativa, desde a sua fundação, também passou a trabalhar em prol de outros dois objetivos bastante importantes: a produção agroindustrial e a preservação da cultura dos suábios do Danúbio, no que se inclui a língua. Desse modo, é possível compreender a importância da CAA para a comunidade, além disso, é preciso acrescentar que esta é a mantenedora do Colégio Imperatriz Dona Leopoldina. Segundo uma das participantes, "a Agrária é a chefe de todos os funcionários do colégio", e como se trata de uma cooperativa conhecida nacionalmente, pois é a maior produtora de malte do país, seu padrão de qualidade é bastante rígido.

Esse padrão é estendido ao colégio, que tem metas a seguir. Uma delas é o maior número possível de aprovação nas provas Deutsches Sprachdiplom (DSD) - testes de proficiência em língua alemã explicados abaixo. A mantenedora estabelece as metas, mas não influencia, segundo Pedro, representante da CAA, a escolha da metodologia, dos docentes e muito menos da condução das aulas; essas questões ficam todas a cargo da direção e da equipe pedagógica do colégio. Apesar desse posicionamento da CAA, do seu compromisso com a manutenção da cultura dos suábios e da responsabilidade por manter a língua dos imigrantes, ele entende que, na instituição escolar, deve-se ensinar Hochdeutsch e não o Schwowisch; "este deve ser ensinado em casa pelos pais". Entendida, de modo geral, a relação existente entre o colégio e a CAA fechamos aqui o parêntese.

O Schwowisch é uma variedade da língua alemã utilizada no dia a dia pelos suábios do Danúbio na Colônia, que já sofreu muitas alte- 
rações em sua forma de realização em virtude do contato com a língua portuguesa. Segundo a participante Jane, a variedade local de língua alemã tem se distanciado cada vez mais do alemão clássico, especialmente na pronúncia. Essa discrepância se torna evidente nas aulas de Hochdeutsch, quando os alunos falantes nativos de Schwowisch misturam a pronúncia deste com a do Hochdeutsch.

A questão é bastante complexa e até mesmo controversa, pois, de acordo com as informações dadas pela equipe pedagógica, a variedade de alemão falada pelos imigrantes e seus descendentes não é trabalhada na escola, em vez deste, prioriza-se o alemão padrão, idioma que as crianças, ao chegarem à escola, desconhecem tanto quanto o português. Não se pode dizer, no entanto, que o uso da variedade de alemão é propriamente proibido, pois prioriza-se o Hochdeutsch e evita-se o Schwowisch. Assim, a variedade local de língua alemã não tem espaço na escola e esse lugar ou não lugar é determinado pela coordenação pedagógica e pela coordenação da área de alemão, endossado pelo PPP.

A substituição do Schwowisch pelo Hochdeutsch realizada pela escola é justificada pelos profissionais que trabalham com a língua alemã na instituição e pela coordenação pedagógica, uma vez que ela é considerada "a única possibilidade, tendo em vista que esta é a língua culta"; em outras palavras, "não tem como trabalhar em sala o Schwowisch, pois é só um dialeto". De certo modo, essa substituição resolve um problema comum a muitas colônias de imigrantes: manter-se ligada ao passado, honrando os ascendentes e, ao mesmo tempo, seguir "olhando em frente", estabelecendo novas relações pensando no futuro.

Dessa forma, podemos dizer que o Colégio Imperatriz Dona Leopoldina conseguiu estabelecer um meio-termo entre a possibilidade de assimilação total pela cultura brasileira (representada pela substituição do Schwowisch pelo português e o desaparecimento total daquele), o que implica, de certa forma, abrir mão da identidade suábia e a permanência em um estado de isolamento total em relação ao entorno (representada pelo monolinguismo em Schwowisch). Isso foi possível ao se adotar o Hochdeutsch como língua de ensino, fazendo com que a comunidade passasse a se identificar com ele. Fato que nos mostra as escolhas linguísticas ideais da comunidade direcionando o trabalho com línguas na escola: a variedade de alemão falada ali pelos suábios, em relação ao alemão oficial, perde seu prestígio. 
Segundo informações da equipe pedagógica, os educandos estudam o alemão padrão durante toda a Educação Básica no Colégio Imperatriz e, ao longo de sua formação, fazem exames de proficiência, que vêm da Alemanha e são reconhecidos internacionalmente, os quais certificam a proficiência em língua alemã, as provas DSD: o primeiro Exame chama-se Zentrale Deutschprüfung (Nível A2); o segundo, Deutsches Sprachdiplom (Nível B1); e o terceiro, Deutsches Sprachdiplom (Nível C1). ${ }^{1}$ Esses níveis tomam como base, segundo a parte do PPP do Colégio Imperatriz Dona Leopoldina que se refere ao ensino de língua alemã, o Quadro Europeu Comum de Referência para as línguas (QECR).

O Colégio Imperatriz, em razão de seu compromisso assumido com a comunidade de ensinar a língua alemã padrão, de modo que os alunos tenham desempenho satisfatório nesses exames, empenha-se, desde a educação infantil, com crianças de dois anos em diante, para cumprir esse propósito. Desse modo, as crianças têm contato com a língua alemã padrão já no primeiro dia de aula na escola, tendo em vista que algumas são falantes nativos de Schwowisch e/ou de português. Conforme afirmam Eliane e Jane, professoras de língua alemã, o trabalho com o Hochdeutsch, nessa fase da educação na escola, é desenvolvido de forma lúdica, uma vez que os professores promovem "brincadeiras e jogos, utilizando-se de músicas, imagens e brinquedos para construir o aprendizado". Segundo os professores participantes da pesquisa, "constrói-se um ambiente favorável à aprendizagem e introdução de forma gradativa de vocabulário e estruturas básicas da língua alemã". Os objetivos que motivam esse trabalho visam à sensibilização da língua alemã. Para Eliane, no colégio, há o objetivo de estudar a língua alemã de maneira que as crianças apreendam um vocabulário satisfatório, que lhes dê suporte para os níveis mais avançados de aprendizado da língua, além de propiciar-lhes o desenvolvimento de conhecimentos do nível básico da língua estrangeira, conforme se observa na fala abaixo transcrita:

A minha parte no Kindergarten [jardim de infância] é introduzir a língua alemã bem como motivar os alunos a gostarem da língua. Então, o que eu faço? Eu trabalho muito com brincadeiras, jogos que são formas de se trabalhar com criança pequena. [...] Essa seria 
a importância dessa fase: que os alunos saiam da educação infantil gostando de alemão e sintam prazer em estudar a língua, além de terem bastante vocabulário. Depois, quando eles começarem a escrever no primeiro ano e segundo ano do fundamental, já têm um bom conhecimento nessa área de vocabulário e sabem falar as coisas básicas do alemão. (Eliane. Entrevista concedida em 14 de outubro de 2011)

Esse trabalho ainda é fundamental para "incentivar os alunos a gostarem do alemão" e irem para os outros níveis de educação com interesse em aprender mais, sabendo que o Schwowisch deve restringir-se apenas aos contatos informais, sendo utilizado apenas em casa e entre amigos fora da instituição escolar e que deve ser mantido como língua de herança ${ }^{2}$ (Soares, 2012). A condução desse trabalho, segundo Jane, é apoiada e exigida pela CAA, tendo em vista que os alunos do colégio são funcionários em potencial da empresa e, por isso, devem saber interagir em alemão padrão em virtude dos contatos da empresa com a Alemanha.

Nesse contexto, a disciplina de língua portuguesa, apesar da carga horária considerável (seis aulas semanais em todas as turmas do Ensino Fundamental II e do Ensino Médio), parece receber menos atenção (em comparação com a da língua alemã) no Colégio Imperatriz Dona Leopoldina no que se refere ao ensino e ao espaço ocupado pelos docentes. Embora sejam comuns entre os colonos e, sobretudo, entre a equipe pedagógica do Colégio Imperatriz Dona Leopoldina, os comentários sobre a importância de comunicar-se de maneira eficiente em língua portuguesa, não se enfatiza a realização de um trabalho sistemático ou diferenciado com essa língua. Segundo Anderson, coordenador pedagógico, a língua portuguesa, por ser oficial do país e materna da grande maioria dos brasileiros, "obrigatoriamente está em qualquer escola, não é um diferencial”, isso quer dizer que não se pode optar por estudar ou não o português nas instituições escolares brasileiras, todos precisam estudá-la, querendo ou não. É uma língua que beneficia os colonos por ser a forma de contato com os "brasileiros" e uma forma de, na sociedade brasileira, angariar maior status; no entanto, "não precisa receber grande ênfase", pois seu lugar já está garantido no Colégio e em qualquer outro no território brasileiro. Está garantido também e, em es- 
pecial, porque a comunidade escolar faz uso da língua portuguesa para a grande maioria de atividades na colônia, dentro e fora das instituições, poucos são os que não têm domínio dessa língua no local.

As políticas linguísticas assim pensadas e postas em prática, por meio do planejamento linguístico do PPP, demonstram que estão muito ligadas ao que a população local considera importante, ou seja, elas partem daquilo a que os suábios atribuem valor, um valor construído com base nas relações que eles mantêm entre si, com a comunidade externa de entorno e com a Alemanha. Por isso, unimos as políticas linguísticas às crenças, demonstrando que as atitudes linguísticas são influenciadas e, ao mesmo tempo, reforçadoras daquelas.

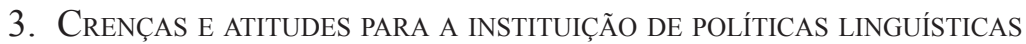 LOCAIS}

Para especificar o nosso ponto de vista neste artigo, sobre o que denominamos crenças assim como Política e Planejamento Linguístico, trazemos alguns autores cujas discussões contribuíram para a reflexão ora proposta.

Iniciamos com a discussão sobre crenças, evocando o conceito teórico escolhido que mais atende aos objetivos da pesquisa realizada. Torna-se importante essa especificação, pois a expressão é amplamente utilizada em várias áreas do conhecimento, assumindo, em cada uma, contornos diferenciados. De acordo com Barcelos (2006), o termo faz referência a um conceito que não se presta muito a investigações tradicionais por ser um fenômeno bastante complexo e controverso. Para a autora, mesmo em Linguística Aplicada, não há um consenso a respeito do conceito. Ainda assim, ela nos fornece uma definição esclarecedora, segundo a qual é possível ver as crenças "como uma forma de pensamento, como construções da realidade, maneiras de ver e perceber o mundo e seus fenômenos, coconstruídas em nossas experiências e resultantes de um processo interativo de interpretação e (re)significação" (p. 18).

Trata-se de uma construção social, dinâmica, mediada e situada contextualmente. Dinâmica, porque as crenças podem mudar ao longo do tempo e da interação entre pessoas. Situada contextualmente, pois as crenças não são estruturas mentais acabadas, mas em constante mu- 
tação "à medida que interagimos e modificamos nossas experiências e somos, ao mesmo tempo, modificados por elas". E mediada, porquanto as crenças, segundo Barcelos (2006), "podem ser vistas como instrumentos, ferramentas disponíveis, as quais podemos usar ou não dependendo da situação, tarefa e pessoas interagindo conosco". No ensino de línguas, elas "podem agir como instrumentos de empoderamento ou como obstáculos para o [processo de] ensino/aprendizagem" (p. 19-20).

No que se refere mais especificamente ao processo de ensino-aprendizagem de línguas, as crenças trazem implicações importantes para entender as relações entre professor e alunos e a cultura da sala de aula com o contexto (BARCELOS, 2004). Elas são "fatores que vêm determinar as estratégias escolhidas para se lidar com o insumo apresentado e com as atividades propostas". Além disso, Madeira (2005, p. 352) afirma que "levam o indivíduo a escolher as ferramentas cognitivas para a definição e posterior solução de um problema". Observar o estabelecimento de políticas linguísticas e, como reflexo disso, o ensino de língua pelo viés das crenças envolve considerar além dos componentes social e linguístico, o componente afetivo (MadeIra, 2005). Segundo o autor, "questões afetivas [...] podem incluir bloqueios e identificação com cultura-alvo; hábitos arraigados podem envolver afetividades com professores ou cultura regional" (p. 354).

Nesse sentido, é imprescindível detectar as crenças dos indivíduos participantes da pesquisa, visto que elas dão possibilidade para entender com quais línguas se identificam os indivíduos na colônia e por que, por exemplo, o ensino de alemão gera "usuários eficientes do idioma", segundo a coordenação da área de alemão da escola, enquanto o português, não. Além do mais, como afirma Finger (2008), as crenças, em ambientes multilíngues, podem determinar quais línguas são minoritárias e as que têm melhor status. Para a autora, de acordo com a forma como são interpretadas e postas em prática, "as crenças envolvidas no ensino influenciam e interferem no processo que se realiza, o julgamento que é feito pelo professor no ensino de uma língua minoritária assume um papel decisivo no processo de socialização e compreensão da língua" (FINGER, 2008).

Assim, é bastante significativo avaliar reflexivamente, como orienta a autora, as atitudes linguísticas de professores e alunos a partir de suas crenças, pois o professor pode desencadear um processo de 
motivação para o estudo de outra língua ou o preconceito linguístico. As atitudes linguísticas dos docentes de línguas, portanto, estão relacionadas à construção de "identidade, atitudes e valores sobre o mundo" (FINGER, 2008). A respeito disso, Aguilera (2008) afirma:

\begin{abstract}
A atitude linguística assumida pelo falante implica a noção de identidade, que se pode definir como a característica ou o conjunto de características que permitem diferenciar um grupo de outro, uma etnia de outra, um povo de outro. A identidade pode ser definida sob duas formas: (i) objetiva, ou seja, caracterizando-a pelas instituições (educacionais, artísticas, políticas, culturais, sociais, religiosas) que a compõem e pelas pautas culturais (usos, costumes, tradições) que lhe dão personalidade; ou (ii) subjetiva, antepondo o sentimento de comunidade partilhado por todos os seus membros e a ideia de diferenciação com respeito aos demais. (p. 105)
\end{abstract}

No caso da Colônia Entre Rios, a instituição da identidade de grupo é definida objetivamente por meio da escola, pensada justamente para reforçar a cultura suábia e a língua alemã em sua variedade padrão. Esses objetivos estão marcados não somente no PPP e nos planejamentos, mas também na fala dos participantes do processo de ensino-aprendizagem de línguas.

No que se refere às Políticas Linguísticas e ao Planejamento Linguístico, abordamos aqui essas noções, segundo o ponto de vista de Calvet (2007), que trata da consolidação de tais conceitos, buscando não somente descrever cientificamente situações multilíngues diversas, como também orientar formas de intervenção por meio de determinados instrumentos de política e planificação linguística. O autor define política linguística como uma determinação proveniente de uma decisão de peso no que se refere às relações entre língua e sociedade e é usada no singular quando se refere mais propriamente às determinações que vêm do Estado que, em geral, defendem uma língua una, sem variações, atacando qualquer ameaça de mescla, como é o caso dos estrangeirismos, por exemplo, camuflando a sua existência. Com base nas políticas linguísticas elaboradas, estabelece-se um planejamento linguístico, ou seja, a intervenção efetiva no uso da língua (CALVET, 2007).

As políticas linguísticas podem endossar uma ocorrência linguística comum a uma determinada comunidade. É o caso, por exemplo, 
de grupos linguísticos ocupantes do território brasileiro, indígenas, imigrantes ou de fronteira, cujas decisões quanto à(s) língua(s) são ditadas pela própria comunidade por meio da instituição da igreja, de conselhos comunitários ou da escola. A esse processo, Calvet (2007) dá o nome de gestão in vivo, pois é uma decisão que provém da prática social, ou seja, "refere-se ao modo como as pessoas resolvem os problemas de comunicação com que se confrontam cotidianamente". A gestão in vivo tanto pode resultar na adoção de uma língua já existente - veicular ou não - alterando seu status, de acordo com o caso salientado acima, quanto resultar em "línguas aproximativas", os pidgins; ambas as possibilidades, criação ou refuncionalização das línguas, não têm a ver com uma decisão oficial (CALVET, 2007, p. 69).

Quando a intervenção é pensada pelo Estado, sem tomar como base a gestão in vivo, a decisão acerca dos usos linguísticos no ambiente plurilíngue é oficial e vertical. Esse é o caso de uma gestão in vitro: "em seus laboratórios, linguistas analisam as situações e as línguas, as descrevem, levantam hipóteses sobre o futuro das situações linguísticas, propostas para solucionar os problemas e, em seguida, os políticos estudam essas hipóteses e propostas, fazem escolhas, as aplicam" (CALvet, 2007, p. 70). O ideal, segundo o autor, é que as duas gestões coincidam, ou seja, que a decisão in vitro reflita alterações que já se processaram in vivo. No entanto, esse processo é ainda incomum no Brasil, está em sua fase inicial, com poucos casos de cooficialização de línguas minoritárias.

4. CRenças sobre o ensino de português e de alemão Permeadas pelas NOÇÕES DE LÍNGUAS DOS PROFESSORES ENTREVISTADOS

As entrevistas feitas nos deram a possibilidade de compreender as crenças dos professores em relação a como deve ser o ensino de alemão e o de português, dando-nos suporte para essas considerações, além de nos mostrarem noções de língua diferenciadas para o Hochdeutsch, o Schwowisch e o português.

Como será possível perceber nas falas do Quadro 2, há sempre uma comparação feita pelos próprios professores de línguas entre as aulas de alemão e as de português, havendo ainda uma discrepância entre a expectativa da instituição e a realização de uma das disciplinas 
em específico, justamente pela comparação existente entre as práticas nas duas disciplinas. Procuramos demonstrar as crenças em um quadro para facilitar a visualização e posterior discussão.

\section{Quadro 2. Crenças dos participantes da pesquisa sobre o ensino de português} e de alemão

\begin{tabular}{|c|c|}
\hline CRENÇAS SOBRE O ENSINO DE PORTUGUÊS & CRENÇAS SOBRE O ENSINO DE ALEMÃO \\
\hline $\begin{array}{l}\text { - Metodologia socioconstrutivista } \\
\text { (Rafael). } \\
\text { - Estudo de diferentes gêneros (Rafael). } \\
\text { Conteúdos gramaticais dentro de uma } \\
\text { análise linguística (Rafael e Amanda). } \\
\text { - Trabalha-se produção de textos em } \\
\text { geral escritos (Andreia). } \\
\text { - Oralidade é enfatizada (Andreia e } \\
\text { Amanda). } \\
\text { - "Eu vejo que infelizmente no portu- } \\
\text { guês, às vezes, o aluno faz oral ou faz } \\
\text { escrito e ponto final. Então esse traba- } \\
\text { lho não contempla o aluno que é talvez } \\
\text { até por uma natureza mais introvertido } \\
\text { ou que não gosta de se expor em sala } \\
\text { de aula, né?” (Marília). } \\
\text { “ “O ensino de português é bem equi- } \\
\text { parado com o alemão, com o mesmo } \\
\text { número de aulas. Em relação ao } \\
\text { número de falantes de português e de } \\
\text { alemão também acho que é igual... Eu } \\
\text { vejo que a língua deve ser usada para a } \\
\text { comunicação uma vez que não é todo } \\
\text { mundo que fala a língua alemã, então o } \\
\text { português acaba sendo necessário para } \\
\text { a comunicação também” (Rafael). } \\
\text { - "Na língua portuguesa, você tem uma } \\
\text { disciplina da grade curricular obriga- } \\
\text { tória, então, vamos dizer assim, esse } \\
\text { vínculo afetivo é, na minha opinião, } \\
\text { necessário/importante, mas pode ser } \\
\text { um pouco mais profissional do que na } \\
\text { língua alemã” (Anderson). }\end{array}$ & $\begin{array}{l}\text { - Na língua alemã, já se trabalha numa } \\
\text { outra corrente, nessa disciplina o ensino } \\
\text { das práticas de interação é bem mais } \\
\text { efetivo em função de serem trabalhadas } \\
\text { as habilidades de ouvir, falar, escrever e } \\
\text { ler (Marília). } \\
\text { - "Eu preciso, obrigatoriamente, na } \\
\text { língua alemã, assim como eu acho que } \\
\text { deveria acontecer na língua inglesa e na } \\
\text { língua espanhola, conquistar o interesse } \\
\text { do aluno para que ele queira se desen- } \\
\text { volver justamente nessa disciplina" } \\
\text { (Anderson). } \\
\text { "No caso da língua alemã, é necessário } \\
\text { fazer uma consideração que vai muito } \\
\text { além do conhecimento técnico, que } \\
\text { se relaciona mais à perspectiva desse } \\
\text { profissional desenvolver o idioma de } \\
\text { forma interativa/de forma interessante } \\
\text { ao educando" (Anderson). } \\
\text { "É uma necessidade de interação muito } \\
\text { maior, não é apenas passar o que está } \\
\text { na apostila, passar o que está no cader- } \\
\text { no, e, sim, uma proposta de construção } \\
\text { de relacionamento, não falo aqui de } \\
\text { relacionamento professor amiguinho do } \\
\text { aluno, mas de um relacionamento sério, } \\
\text { de um relacionamento profissional com } \\
\text { o olhar, o foco para o cliente [aluno] } \\
\text { que em algumas disciplinas obriga- } \\
\text { tórias nem sempre está tão presente" } \\
\text { (Anderson). }\end{array}$ \\
\hline
\end{tabular}

(Continua) 


\begin{tabular}{|c|c|}
\hline CRENÇAS SOBRE O ENSINO DE PORTUGUÊS & CRENÇAS SOBRE O ENSINO DE ALEMÃO \\
\hline $\begin{array}{l}\text { - "Os professores de português dão muita } \\
\text { aula expositiva, despejam os conteúdos } \\
\text { na cabeça do aluno e o aluno vai fazer } \\
\text { o que com isso? O aluno é preparado } \\
\text { para passar em vestibular única e exclu- } \\
\text { sivamente" (Jane). } \\
\text { - "Dificuldade no início de falar o portu- } \\
\text { guês corretamente" (Eliane). }\end{array}$ & 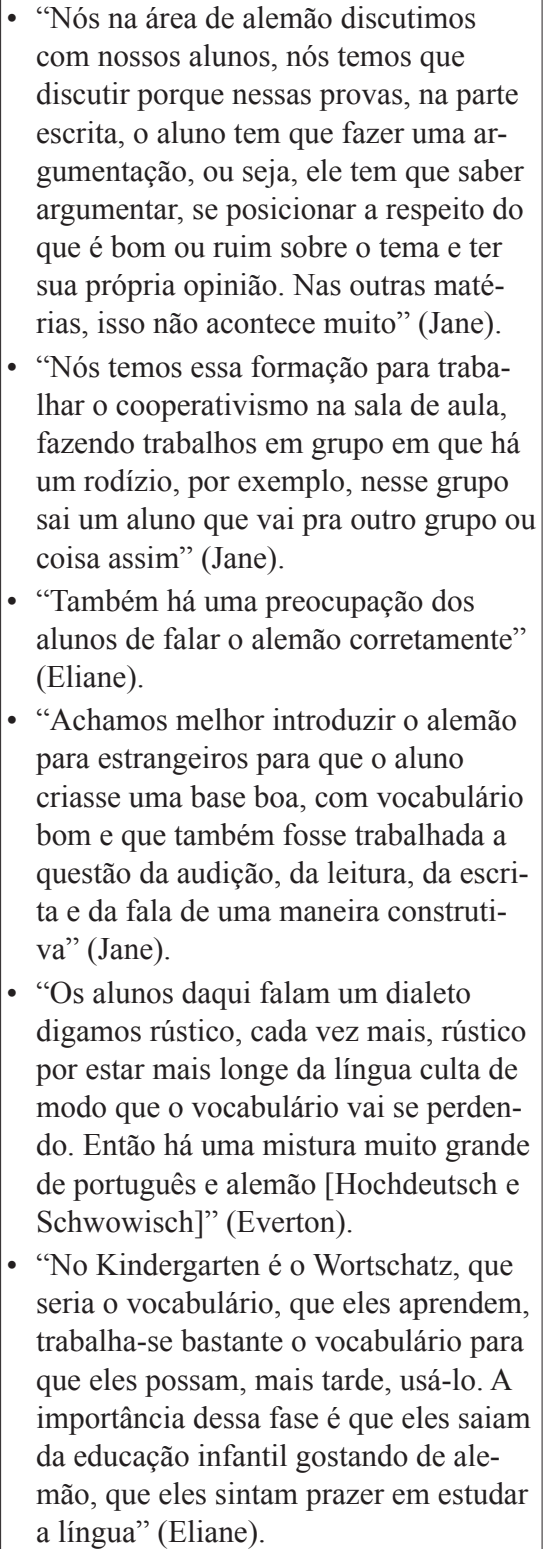 \\
\hline
\end{tabular}


No que se refere ao ensino de alemão, é evidente, pelas falas expostas no Quadro 2, que, para os professores de alemão e para a coordenação pedagógica, ensinar alemão envolve afetividade, pois o professor deve conduzir as aulas de modo que o aluno se sinta atraído pelo estudo dessa língua. A justificativa dada por esses participantes, para um ensino assim configurado, está pautada na comparação com a língua portuguesa, pois esta é obrigatória em qualquer escola e o alemão, não. $\mathrm{O}$ alemão, sendo o diferencial, se não for trabalhado de modo interessante pode afastar os alunos da instituição, os quais, segundo Anderson, são mais que alunos, "são clientes".

Associada a essa preocupação em tornar as aulas interessantes está o que os profissionais chamam de aula interativa, baseada na interação. Essa interação, conforme explicita Jane, pauta-se na "discussão", pois o aluno deve desenvolver a "capacidade de argumentação e saber se posicionar diante dos fatos e informações em alemão". A aula assim desenvolvida facilitaria a preparação dos alunos para as provas DSD que, segundo Jane, exigem essa competência dos candidatos. Nas observações das aulas, notou-se que os professores conversam o tempo inteiro com os alunos, são raros os momentos em que o professor somente expõe conteúdos, estes se mesclam a essas conversas. Trabalhar de modo interativo também significa promover o cooperativismo entre os alunos por meio do trabalho em grupos. Essa crença influencia a prática dos professores, pois, conforme observamos no dia a dia da sala de aula, as atividades da apostila são encaminhadas de modo que os alunos possam se ajudar, uma vez que sentam-se próximos uns dos outros para desenvolvê-las. Nas turmas muito pequenas, é comum todos se ajudarem em um grupo maior.

Essa atitude que reflete a crença do professor, conforme explica Finger (2008), determina a relação que o aluno terá com a língua-alvo, assumindo uma função decisiva para o bom desempenho dele nessa língua. Assim, pode-se compreender por que os educandos se identificam mais com a língua alemã, pois as crenças acerca da língua manifestadas pelos docentes de alemão fazem com que envolvam os alunos de modo afetivo. Madeira (2005), conforme vimos, diz que a afetividade pode gerar identificação com a língua-alvo, o que certamente ocorre nesse caso. 
Quanto à língua alemã, aprendê-la é "aprender vocabulário", como fica claro na fala dos professores de alemão citados no Quadro 2. Essa crença demonstra que, quanto mais vocabulário o aluno dominar, mais apto estará para a interação nessa língua. Segundo Jane, nas provas DSD, entre outras habilidades, o tipo de vocabulário utilizado pelo aluno é avaliado, se é mais básico, trazendo palavras do dia a dia pouco complexas, quando deveria apresentar um nível mais alto, a nota sofrerá consequências; em contrapartida, se as palavras mais complexas forem inseridas no discurso sem hesitações, o aluno vai obter pontos melhores na prova.

Essa crença é bastante importante porque os participantes apontam o vocabulário como um dos itens que distingue o Schwowisch do Hochdeutsch. O vocabulário do Schwowisch, conforme nos explica Everton, está bastante misturado com o português, ou seja, muitas palavras do português fazem parte do Schwowisch. Inclusive, como o mesmo professor nos informa, na própria conjugação de alguns verbos, tende-se a utilizar a raiz do verbo em alemão e as desinências do verbo em português. Essa mistura não é vista com bons olhos pelos professores de alemão, uma vez que essa prática afasta os falantes da língua culta, ou seja, da realização da língua que angaria maior status.

É evidente a coerência entre as expectativas da coordenação pedagógica e as crenças e atitudes dos professores de alemão. Quando Anderson diz, numa das falas do Quadro 2, que é necessário construir um "relacionamento profissional com foco para o cliente/aluno", entendemos que isso ocorre nas aulas de alemão, pois ele completa "que em algumas disciplinas obrigatórias nem sempre está tão presente". Ou seja, o ensino de alemão tem alcançado os objetivos da instituição e da comunidade como um todo, conforme Pedro, representante da mantenedora que traz a visão da CAA sobre o Colégio Imperatriz Dona Leopoldina:

Pedro: nas DSD, os resultados estão acima do esperado. Nós somos o melhor colégio do Brasil, nos anos de 2011 e 2012, nas provas DSD. Então estamos muito satisfeitos com os alunos, pois os resultados na prova de alemão foram acima da expectativa. (Pedro. Entrevista concedida em 11 de dezembro de 2012) 
A pesquisadora, ao afunilar o questionamento para as provas DSD, permite que Pedro enfatize os ótimos resultados nos testes sem compará-los ao desempenho na língua portuguesa. Nesse caso, apesar de a mantenedora mostrar-se satisfeita com o ensino de língua portuguesa, há divergência entre a expectativa da coordenação pedagógica e as crenças dos professores. Esse desacordo se explica pelo fato de os professores terem como perspectiva de ensino o Sociointeracionismo de fundo vygotskyano, segundo o qual, pelo que afirmam Amanda e Rafael, em sala de aula, as práticas de leitura, escrita, oralidade e análise linguística são trabalhadas, ou seja, os participantes dizem que são enfatizadas as práticas de interação e não a estrutura da língua. No entanto, embora esse seja o direcionamento, conforme informam os professores e também Marília, e o material esteja embasado também nessa perspectiva de ensino, temos Andreia, que considera importante trazer "listas de exercícios" sobre a estrutura da língua, como está descrito na fala abaixo, mesmo que a ênfase de sua aula esteja na produção textual, segundo a própria professora:

Andreia: Nós temos seis aulas semanais, a gente trabalha com o apostilado Positivo que traz um bom embasamento, mas, além desse material, eu trabalho bastante com produção de texto, trazendo outros assuntos, trago também a leitura de livros diversos. Os alunos fazem trabalhos e apresentam, pois eu gosto muito que eles trabalhem a oralidade deles para perderem o medo de falar em público que a maioria das pessoas tem. Então, é, nesse sentido, que eu dou ênfase, a gramática tem no material apostilado, além disso, eu trabalho um pouquinho mais de exercícios também, trazendo outras listas de exercícios, mas a ênfase maior seria na comunicação oral e na escrita, isto é, na produção de textos. (ANDREIA. Entrevista concedida em 11 de junho de 2012)

Nessa fala, quando a docente diz "um pouquinho mais de exercícios também, trazendo outras listas de exercícios", há um claro cuidado, por meio do uso da palavra em destaque estar no diminutivo, em não se colocar em franca oposição ao direcionamento metodológico sugerido pelo apostilado. É evidente que ela, embora entenda a importância de se trabalhar a perspectiva sociointeracionista, acredita ser o caminho para uma boa expressão conhecer a gramática. Aliás, essa é 
uma crença comum a muitos professores de língua portuguesa, a qual se opõe à crença dos professores de alemão, tendo em vista que eles entendem o estudo da gramática como mais uma dentre todas as práticas de sala de aula, cujas questões são trabalhadas a partir de textos, sem lançar mão da lista de exercícios.

Se considerarmos a prática de oralidade abordada pelas professoras Amanda e Andreia, notamos um distanciamento da expectativa de Marília, pois, segundo as docentes, é enfatizado o trabalho com a oralidade. Na entrevista com Andreia, ela nos conta que trabalha a oralidade com os alunos, mas não informa como isso é feito. Nas observações realizadas nas aulas da professora, comprovou-se que ela conduz apresentações de seminários sobre livros literários de escolha dos alunos, trabalho desenvolvido e apresentado na biblioteca do Colégio. Já, para Amanda, trabalhar a oralidade é deixar os alunos participarem das aulas, contribuírem com as suas opiniões sobre o tema do dia, conforme ela explicita na fala abaixo mais especificamente nos trechos em destaque:

Amanda: bastante, procuro trabalhar bastante [a oralidade], eu procuro não fazê-los lerem tanto a apostila, acompanhando ali. Tanto que eu preparo no meu diário que é uma prática minha de classe, a aula, mesmo sendo da apostila, eu leio e preparo a aula, pensando de modo que eles falem, nesse caso, eu vou instigando-os a falarem. Como na aula de hoje sobre conto em que eu tentei deixá-los falar ao máximo. Assim, nessa questão, eu procuro trabalhar a oralidade deixando que eles falem à vontade, não limito/não direciono muito. (AMANDA. Entrevista concedida em 23 de abril de 2012)

Nesse quesito, o ensino de língua portuguesa e o de língua alemã estariam se desenvolvendo numa mesma perspectiva; no entanto, pela fala de Marília, em língua alemã, o objetivo se efetiva e em português ainda não. Percebemos na fala de Jane que há a crença de que a aula de língua portuguesa é expositiva e que seu foco é conteudístico. A respeito disso, cabe aqui lembrar o que dizem os alunos entrevistados, segundo os quais, o trabalho com a língua portuguesa enfatiza a gramática, eles colocam a língua portuguesa em lugar oposto ao de alemão, pois "nas aulas de alemão são trabalhadas questões que são úteis no dia a dia" e em português é "mais gramática". A partir disso, é possível notar 
que as crenças distintas dos professores modificam a atitude dos alunos perante as línguas e, consequentemente, suas crenças sobre o que é ou não um bom trabalho com língua.

Assim, como as informações não se complementam, está claro que há algo que não garante credibilidade ao ensino de língua portuguesa, dentro da própria instituição escolar, a qual, pelos dados coletados, não é possível explicar. Essa divergência fica no âmbito da instituição mesmo, tendo em vista que, para Pedro, o ensino em geral na escola tem avançado nos últimos anos, pois o colégio obteve bons resultados no ENEM, prova que inclui a língua portuguesa. Embora Pedro não se refira diretamente à língua portuguesa, ao dizer que as médias dos alunos no ENEM melhoraram, podemos entender que tiveram resultados melhorados nos conhecimentos de todas as disciplinas. Outra crença salientada, sobretudo por Anderson, em relação ao ensino de língua portuguesa, refere-se a ser menos necessário construir um vínculo afetivo entre a língua e os alunos, pois se trata de uma língua cujo ensino é obrigatório. Nesse caso, não haveria questionamento por parte dos pais e dos alunos sobre a necessidade de se abordar essa língua na escola.

Ainda sobre o ensino de língua portuguesa, notamos que os docentes conhecem bem a base teórica do material de apoio escolhido pela escola e que procuram trabalhar a partir dela também, orientando sua prática de um modo sociointerativo. No entanto, essa é uma dificuldade não somente dos professores da instituição participante da pesquisa, subjaz a essa prática a crença de que ensinar língua portuguesa é ensinar gramática, tanto é que os três professores dizem que a gramática está presente ou em forma de análise linguística ou em forma de listas de exercícios de estrutura.

Ensinar gramática está tão impregnado na essência - se é que existe uma - do professor de português que não trabalhar de modo explícito com ela parece dizer que não se está fazendo nada, não se está ensinando língua portuguesa. Esse conflito, muitas vezes, é gerado ainda na formação dos professores - não somente os do Colégio Imperatriz - como afirma Jane. Refletindo de outra forma, nenhum profissional, por melhor que seja sua formação, chegando ao seu local de trabalho, não está pronto, vai ser forjado na prática, com a experiência do dia a dia. Nesse caso, percebe-se a necessidade de estudo contínuo, com a realização de cursos, por exemplo, para a formação continuada 
dos profissionais de acordo com o tipo de prática que eles desenvolvem na instituição.

Dessa forma, essas crenças estão pautadas tanto no ensino de língua alemã quanto no de língua portuguesa e são elas, entre outras não abordadas aqui, que direcionaram e direcionam o PPP da instituição para o ensino de línguas. Esse documento também pode ser considerado um instrumento de políticas linguísticas, tendo em vista que, a partir das necessidades da comunidade, foi pensado pela equipe do colégio como uma forma de suprir tais necessidades e regula as atitudes em relação às línguas. Nele está contemplado um ensino de língua alemã diferenciado, primeiro porque os professores de alemão estão organizados em uma área, ou seja, existe a área de alemão coordenada por um dos docentes, já o português consta no rol das demais disciplinas, no PPP; segundo porque liga o ensino de alemão ao imperativo de se preservar a língua com a qual os suábios da região se identificam.

Essas escolhas são contraditórias, pois a língua estrangeira contemplada no PPP não é a língua local, o suábio, mas a língua da Alemanha, entre as quais, segundo os participantes, há sensíveis diferenças. Se pensarmos que o suábio é a língua de herança da comunidade local, poderíamos imaginar que essa é a língua que os identifica com os descendentes; no entanto, por acreditarem que a língua alemã tem reconhecimento mundial, sendo, de fato, uma língua - diferente do suábio que, para eles, é apenas um dialeto - elegeram-na para ser ensinada na escola. Nesse sentido, notamos uma tentativa de a comunidade ser ouvida e valorizada, sendo associada com o povo de tal país, isso acaba ocorrendo na região de entorno de Entre Rios, pois, como os detalhes vistos aqui não estão explícitos, a comunidade de entorno designa os colonos como alemães e a língua como alemã.

O trabalho de implantação do Hochdeutsch como língua de ensino no Colégio está embasado no QECR, mais um documento, este internacional, também considerado um instrumento de políticas linguísticas. O Quadro foi elaborado pelo Conselho da Europa a partir do projeto "Políticas Linguísticas para uma Europa Multilíngue e Multicultural" e "constitui, juntamente com o Portfolio Europeu das Línguas, um instrumento linguístico essencial para a harmonização do ensino e da aprendizagem das línguas vivas na grande Europa" (Alves, 2001, p. 7). A principal função do QECR é explicitar objetivos e métodos que 
podem ser usados para o benefício dos que o utilizam como referência no processo de ensino-aprendizagem de línguas estrangeiras e respectiva avaliação. Nesse caso, fornece uma base comum para a "elaboração de programas de línguas, linhas de orientação curriculares, exames, manuais, etc., na Europa". Além disso, descreve aquilo que os estudantes devem aprender para serem proficientes nessa língua, definindo, "ainda, os níveis de proficiência que permitem medir os progressos dos aprendentes em todas as etapas da aprendizagem e ao longo da vida" (p. 19). Com base nesses níveis, também fica estabelecida a forma de avaliação que verifica o desempenho dos estudantes em cada um dos níveis, de modo a habilitá-los para o estudo mais avançado na língua.

Assim, é possível dizer que as crenças da comunidade e, mais especificamente, da escola estão na base do ensino de línguas no Colégio, justificando as escolhas implantadas nos sistema de ensino. São elas também que direcionam o trabalho metodológico com cada língua e, como são distintas para a língua portuguesa e a para a língua alemã, reforçam atitudes de valorização desta, relegando aquela ao espaço de língua oficial do Brasil que deve ser ensinada, não necessariamente de um modo diferenciado, tendo em vista que a obrigatoriedade de seu ensino já justifica sua presença na escola.

É importante salientar, por fim, que não nos colocamos em favor da prática de nenhum dos grupos, de português ou de alemão, procuramos analisar o que vimos com a aplicação da metodologia. Não queremos separá-los, e não o fazemos aqui, isto é, valorizando um em detrimento do outro; procuramos apenas apresentar as crenças que permeiam as práticas e direcionam a atitude dos alunos em relação às línguas em questão.

\section{CONSIDERAÇÕES FINAIS}

A partir do exposto acima, podemos afirmar que a Colônia Entre Rios é um lugar onde o uso das línguas é complexo e conflituoso. Dentro dele, trabalhar língua portuguesa ou língua alemã não é apenas ensinar línguas, é também mexer na estrutura e nos tipos de contatos estabelecidos entre os falantes de línguas diferentes, atuar sobre as crenças do outro, impor as suas crenças - e isso não acontece somente em Entre 
Rios. Desse modo, dar condições para o professor atuar nesse ambiente é a palavra de ordem e isso nenhuma formação genérica vai possibilitar.

Vale ressaltar que as ideias da Colônia têm sido colocadas em prática, as políticas linguísticas pensadas para resolver as demandas linguísticas da comunidade têm se efetivado por meio do planejamento linguístico cujo instrumento principal é o Colégio Imperatriz Dona Leopoldina e o seu PPP. Ainda que tenha ocorrido a substituição do Schwowisch pelo Hochdeutsch dentro da escola, entendemos que esse foi um recurso da comunidade para resolver uma das principais questões que envolvem as colônias de imigração: como manter-se ligada ao passado, honrando sua cultura de origem e os ascendentes e, ao mesmo tempo, voltar os olhos para o presente e para futuro quando a língua portuguesa tem ganhado mais espaço num movimento praticamente inevitável?

O Colégio, como se pode perceber, consegue estabelecer um equilíbrio entre a possibilidade de assimilação total pela cultura brasileira (representada pela substituição do Schwowisch pelo português) e o isolamento em relação ao entorno (representada pelo monolinguismo em Schwowisch, somente referenciado na época de início da colonização da região): a solução, como pudemos testemunhar, foi a adoção do Hochdeutsch como língua de ensino, levando a comunidade a se identificar com essa língua. Em outras palavras, substituindo o Schwowisch pelo Hochdeutsch, a instituição escolar conseguiu harmonizar o passado com o futuro, sinalizando também para uma inserção cada vez maior da língua portuguesa na comunidade a exemplo do que já acontece na escola.

Desse modo, notamos que o ensino de línguas na instituição está assentado em crenças da população sobre o que é agradável e produtivo para a comunidade. E é com base nessas crenças que as políticas linguísticas são instituídas, mantidas e reforçadas dentro da instituição escolar. 
LiNGUISTIC POLICIES, BELIEFS AND ATTITUDES IN MULTILINGUAL CONTEXT

\section{ABSTRACT}

In this article, we demonstrate how the relation between language policies adopted by the Cologne Entre Rios - Guarapuava/PR and beliefs of speakers of different languages in contact in that region is. Given such reflection we also approach language teaching starting from the influence of this relation, trying to show that the linguistic hybridization not cooperate for the ideal bilingualism (Portuguese/German classic), on the contrary it hinders this practice, being the local variety of German responsible for conducting the classic German problematic. To do so, we support ourselves mainly on guidelines of Calvet (2007), Finger (2008) and Barcelos (2004; 2006).

KEY WORDS: linguistic policies, linguistics beliefs and attitudes, teaching language, multilingual context.

\section{NOTAS}

1 Exame Central de língua alemã (A2), Diploma da Língua Alemã (B1) e Diploma da Língua Alemã (C1) (Tradução de Eliane).

2 Segundo Soares, língua de "herança" está associada a um passado e não a algo futuro, "evocando os conceitos de antigo, primitivo versus moderno e tecnológico" (2012, p. 11). No caso em questão, o Schwowisch, a língua de herança, representa para a comunidade de Entre Rios o primitivo versus o Hochdeutsch, identificado como o moderno e tecnológico.

\section{REFERÊNCIAS}

A AgrÁRIA... Disponível em: < http://www.agraria.com.br/brasil/pagina.ph $\mathrm{p}$ ?menu=institucional\&banner=institucional\&institucional=instit suabios>. Acesso em: 6 fev. 2012.

Aguilera, V. Crenças e atitudes linguísticas: o que dizem os falantes das capitais brasileiras. Revista Estudos Linguísticos, p. 105-112, maio/ago. 2008.

Alves, J. M. (Dir.). Quadro europeu de referência para as línguas: aprendizagem, ensino, avaliação. Tradução de Maria Joana Pimentel do Rosário e de Nuno Verdial Soares. Portugal: Edições ASA, 2001. 
Barcelos, A. M. F. Crenças sobre aprendizagem de línguas, Linguística Aplicada e ensino de línguas. Revista Linguagem \& Ensino, v. 7, n. 1, Pelotas, RS, p. 123-156, 2004.

Barcelos, A. M. F. Cognição de professores e alunos: tendências recentes na pesquisa de crenças sobre o ensino e aprendizagem de línguas. In: BARCELOS, A. M. F.; Abrahão, M. H. V. (Orgs.). Crenças e ensino de línguas: foco no professor, no aluno e na formação de professores. São Paulo: Pontes, 2006.

CAlvet, L. As políticas linguísticas. Tradução de Isabel de Oliveira Duarte, Jonas Tenfen e Marcos Bagno. São Paulo: Parábola Editorial; IPOL, 2007.

Elfes, A. Suábios no Paraná. Curitiba, PR: [s/n], 1971.

FInGER, L. Contexto multilíngue: conduta avaliativa e atitudes linguísticas. A influência de crenças e políticas. Revista Contingentia, v. 3, n. 1, Porto Alegre/RS, 2008. Disponível em: <http://seer.ufrgs.br/contingentia/article/ view/4158/2950\#capitulo2topo>. Acesso em: 10 jul. 2012.

Luersen, R. W. A situação de contato plurilíngue no sul do Brasil. Revista Cientifica da Faculdade Salesiana Maria Auxiliadora, v. 1, jan./jun. 2010. Disponível em: <http://www.fsma.edu.br/visoes/ed08/Edicao_8_artigo_4. pdf $>$. Acesso em: 10 jul. 2012.

MadeirA, F. Alguns comentários sobre a pesquisa de crenças no contexto de aprendizagem de língua estrangeira. Revista Estudos Linguísticos XXXIV, p. 350-355, 2005.

Moita Lopes, L. P. Uma linguística aplicada mestiça e idológica: interrogando o campo como linguista aplicado. In: (Org.). Por uma linguística aplicada indisciplinar. 2 ed. São Paulo: Parábola Editorial, 2006.

O ColÉGIO... Disponível em: <http://www.colegioimperatriz.net.br/historico. asp>. Acesso em: 17 jul. 2011.

Oliveira, G. M. Declaração universal dos direitos linguísticos. Associação de Leitura do Brasil (ALB). Florianópolis: IPOL, 2003.

Revista Linguasagem. São Paulo: UFSCAR, 2009b. Disponível em: <www. letras.ufscar.br/linguasagem>. Acesso em: 11 maio 2012.

PAYER, M. O. Memória da língua: imigração e nacionalidade. Tese (Doutorado em Linguística) - Universidade Estadual de Campinas, Instituto de Estudos da Linguagem, Campinas, SP: [s/n], 1999.

Soares, S. M. C. C. Português língua de herança: da teoria à prática. Dissertação (Mestrado em Português Língua Segunda/Língua Estrangeira) Faculdade de Letras, Universidade do Porto, Portugal, [s/n], 2012. 


\section{ENTREVISTAS}

AmANDA. Entrevista concedida em 23 de abril de 2012.

ANDERSON. Entrevista concedida em 26 de junho de 2012.

ANDREIA. Entrevista concedida em 11 de junho de 2012.

Eliane. Entrevista concedida em 14 de outubro de 2011.

EVERTON. Entrevista concedida em 13 de junho de 2012.

JANE. Entrevista concedida em 21 de outubro de 2011.

Marília. Entrevista concedida em 3 de agosto de 2012.

Pedro. Entrevista concedida em 11 de dezembro de 2012.

Rafael. Entrevista concedida em 7 de agosto de 2012. 